http://dx.doi.org/10.15762/ZH.2015.38

EDMUND KIZIK

(Instytut Historii PAN)

\title{
GDAŃSKI INWENTARZ POŚMIERTNY TORUŃSKIEGO DRUKARZA JOHANNA CHRISTOPHA JUNGMANNA Z 1778 ROKU
}

Słowa kluczowe: dzieje drukarstwa, Prusy Królewskie, Śląsk, XVIII w., postępowanie spadkowe, pogrzeby, Gdańsk, Toruń

W Archiwum Państwowym w Gdańsku, w aktach prezydującego burmistrza, znajduje się pakiet $\mathrm{z}$ dokumentami związanymi z postępowaniem spadkowym po zmarłym w 27 X 1778 r. w Gdańsku toruńskim drukarzu Johannie Christophie Jungmannie ${ }^{1}$. Pochodzący ze Śląska J.Ch. Jungmann zamieszkiwał w domu Daniela Prebersa przy ul. Kocurki, a został pogrzebany w przedmiejskim kalwińskim kościele św. św. Piotra i Pawła².

Dysponujemy jedynie dość skąpymi informacjami dotyczącymi biografii J.Ch. Jungmanna, dla którego z tego zapewne powodu poskąpiono dotychczas miejsca w Toruńskim słowniku biograficznym³. Urodził się zapewne około 1700 r. i nie wiadomo, gdzie uczył się sztuki drukarskiej. Dopiero podjęcie działalności wydawniczej w Jaworze na Śląsku przed 1730 r. skutkuje bliższymi informacjami ${ }^{4}$. Pierwsze znane publikacje J.Ch. Jungmanna ukazały się zapewne przed końcem 1729 r. Są to okazjonalne druki autorstwa teologa i pastora Melchiora Gottlieba Minora oraz Johanna Gottlieba Kalinskiego na śmierć Christiana Klugego, kupca w Kamiennej Górze, zmarłego w sierpniu 1729 r. ${ }^{5}$ Pojawiająca się w literaturze

${ }^{1}$ Archiwum Państwowe w Gdańsku (dalej cyt. APGd.), sygn. 300, 1/156, 163-179.

${ }^{2}$ Niestety, księga zmarłych gdańskiego kościoła św. św. Piotra i Pawła dla XVIII w. nie zachowała się. Pochówek w kościele kalwińskim nie musi świadczyć o wyznaniu zmarłego, który korzystając z kontaktów osobistych, mógł wykupić pochówek w kwaterze kościelnej.

${ }^{3}$ Toruński słownik biograficzny, red. Krzysztof Mikulski, t. 1-7, Toruń 1998-2014 (według indeksu w: ibid., t. 7, s. 282). Nie odnotowuje go również: Słownik biograficzny Pomorza Nadwiślańskiego, t. 1-4, Suplementy 1-3, red. Stanisław Gierszewski (t. 1-2), Zbigniew NowaK (t. 2-4, Suplement 1-2), Józef Borzyszkowski (Suplement 3), Gdańsk 1992-2012.

${ }^{4} \mathrm{~W}$ literaturze przyjęto, że J.Ch. Jungmann działał w Jaworze od 1730 r., zob. Drukarze dawnej Polski od XV do XVIII wieku, t. 4: Pomorze, red. Alodia Kawecka-Gryczowa, Krystyna KorotajowA, Wrocław-Kraków 1962, s. 178-179.

${ }^{5}$ Melchior Gottlieb Minor, Die wohlgegründete Hoffnung der Gläubigen zur ewigen Seeligkeit: wurde Bey der Baare Des [...] Herrn Christian Kluges Vornehmen Kaufmans in Landeshutte [...] Welcher Anno MDCCXXIX. den 24. Aug. [...] sanfte und seelig entschlafen war, Jauer [około 1729 r.] (Biblioteka

$$
\text { Ww.zapiskihistoryczne.pl }
$$


przedmiotu informacja o założeniu przez Jungmanna filii drukarni w Bolesławcu nie jest potwierdzona ${ }^{6}$. Poza literaturą historyczną (przede wszystkim sławnymi „Rocznikami Legnickimi”, dziełem Georga Thebesiusa ${ }^{7}$ z pras drukarni w Jaworze wychodziła przede wszystkim okolicznościowa poezja rodzinna ${ }^{8}$. Nieznane są okoliczności zakończenia kariery w Jaworze: w 1748 r. oficynę przejął Heinrich Müller. J.Ch. Jungmann zapewne próbował szczęścia w Legnicy, tak przynajmniej podaje Zygmunt Mocarski, lecz nie można przypisać mu żadnych tamtejszych druków. Za Z. Mocarskim wiadomo, że po przybyciu do Torunia drukarz 29 IX $1750 \mathrm{r}$. $\mathrm{z}$ toruńską radą miejską zawarł umowę na dzierżawienie tamtejszej oficyny9 . Poprzednikiem J.Ch. Jungmanna był Teophil Ehrenfried Wätzold, który prowadził ją do $1750 \mathrm{r}$. Umowa zawarta początkowo na trzy lata została przedłużona na następne lata ${ }^{10}$. Jednak mimo stosunkowo niezłej opinii o poziomie swojej produkcji J.Ch. Jungmann nie był w stanie utrzymać drukarni, którą w 1759 r. ${ }^{11}$ przejął rajca Christian Friedrich Kunzen. Oficyna J.Ch. Jungmanna prowadziła stosunkowo ograniczoną działalność, lecz cieszyła się uznaniem, a jego druki wyróżniały się dużą starannością. W niespełna 9 lat spod pras drukarni J.Ch. Jungmanna wyszło raptem 36 tytułów (81 arkuszy), w tym niemiecki kancjonał toruński (1752) ${ }^{12}$ opublikowany w nakładzie 4000 egzemplarzy, jak również okolicznościowy utwór dla uczczenia obchodów trzechsetlecia połączenia Prus z Koroną w 1754 r. ${ }^{13}$ We-

Uniwersytetu Wrocławskiego, sygn. 565107); M. Johann Gottlieb KaLINSKY, Die Gestalt eines wahren Klugen in Christo ward bey dem Leichen-Begaengniss des [...] Herrn Christian Kluges [...] welches Anno MDCCXXIX. den 26. Aug. mit christl. Ceremonien gehalten wurde, Jauer [około 1729 r.].

${ }^{6}$ Drukarze dawnej Polski od XV do XVIII, t. 4, s. 178.

${ }^{7}$ Np. [Georg Thebesius], Weyland George Thebesii [...] Liegnitzische Jahr-Bücher: Worinnen so wohl die Merckwürdigkeiten dieser Stadt, Als auch die Geschichte der Piastischen Hertzoge in Schlesien, von ihrem Anfange biß zum Ende des 16. Jahrhunderts [...] untersuchet [...] [Schlesische Chronica, worinnen die Geschichte der piastischen Herzoge [...] enthalten, hrsg. v. Gottfried Balthasar ScharfF], Bd. 1-3, Jauer 1733; Gottfried Stutz, Silesia Numismatica Oder Das Schlesische Müntz-Wesen: Nach seinem Ersten Anfange, Fortgange [...] gefundenen [...] Müntzen; Bey Gelegenheit einiger entdeckten raren Stücke A. 1739. den 2, 3, 4, 5 Nov. in einem Dramate kürtzlich vorgestellet, Jauer 1739.

${ }^{8}$ Zygmunt Mocarski, Książka w Toruniu do 1793 r. Zarys dziejów, [in:] Dzieje Torunia. Praca zbiorowa $z$ okazji 700-lecia miasta, red. Kazimierz TyMieniecki, Toruń-Poznań 1933 [druk: 1934], s. 445. Niewiele nowych informacji podaje: Alojzy Tuјакоwsкi, $Z$ dziejów drukarstwa i piśmiennictwa na Pomorzu. 400 lat drukarstwa i piśmiennictwa w Toruniu 1569-1969, Warszawa 1970.

${ }^{9}$ Z. Mocarski, Książka w Toruniu do 1793 r., s. 445 n.

${ }^{10}$ Ibid. Zob. wskazówki archiwalne w: Krzysztof KopıŃsKi, Katalog rękopisów do dziejów księgozbiorów i drukarstwa toruńskiego i pruskiego w zespole archiwalnym Akta miasta Torunia z okresu staropolskiego, Folia Toruniensia, [t.] 5: 2005, s. 98-99, nr 18.

${ }^{11}$ Stanisław Salmonowicz, Dzieje książki i czytelnictwa, [in:] Historia Torunia, t. 2, cz. 3: Między barokiem i oświeceniem (1660-1793), red. Marian Biskup, Toruń 1996, s. 378-379.

${ }^{12}$ Thornisches Kirchen-Gesang-Buch. Nebst einigen, besonders Thornischen, Kirchen-Gebeten, auf christliche Verordnung E. E. E. und Hochweisen Raths Evangelischen Theils, E. e. Ministerio, Thorn 1752.

${ }^{13}$ Memoria saecularis diei quo ante hos trecentos annos Prussia excusso tyrannidis Cruciferorum Iugo in libertatem sese vindicatum iuit ac deinde sub serenissimor, [Thorunii] 1754. Podobizny kart tytułowych reprodukowane zostały w: Z. MocARski, Ksiązka w Toruniu do 1793 r., s. 446-447; idem, Książka w Toruniu do roku 1772, Toruń 1934, s. 104-105. 
dług opinii Z. Mocarskiego pod względem typograficznym był to druk „wytworny”, „najpiękniejszy wytwór książki toruńskiej XVIII wieku” ${ }^{14}$. Wydaje się, że faktyczna produkcja oficyny musiała być wyższa, albowiem z publikowania kilku druków rocznie nie sposób byłoby utrzymać przedsiębiorstwa oraz zarobić na dostatnie życie ${ }^{15}$. Poza drukami zwartymi, książkowymi dochodziły do tego różnego rodzaju druku akcydensowe, obwieszczenia, prywatne druki z poezją okolicznościową, których nie obejmowało rozliczenie $\mathrm{z}$ radą miejską. Jakkolwiek było, nie zmienia to faktu, że zakres działalności J.Ch. Jungmanna pozostawał stosunkowo skromny. I może to właśnie kwestie finansowe stały się powodem zakończenia jego toruńskiej działalności. W każdym razie we wrześniu 1759 r. drukarnię przejął, a następnie zmodernizował Ch.F. Kunzen, który już w następnym roku z inicjatywy Samuela Luthra Gereta rozpoczął drukowanie gazety ogłoszeniowej „Thornische Wöchentliche Nachrichten und Anzeigen"16. Bez wątpienia nastąpiła w ten sposób znacząca intensyfikacja działalności ${ }^{17}$. A J.Ch. Jungmann opuścił Toruń, lecz $\mathrm{z}$ dostępnych informacji biograficznych nie sposób ustalić, co porabiał i z czego się utrzymywał w Gdańsku czy gdziekolwiek przez następne 18 lat. Zmarł w Gdańsku w samotności, gdyż jego dorosły syn Gottfried mieszkał w niedalekim Tczewie. Nie dysponujemy informacjami o roku zgonu żony J.Ch. Jungmanna.

Niemniej z opisu inwentarza rzeczy po zmarłym wynika, że w dalszym ciągu podawał się za drukarza $z$ Torunia („Buchdrucker in Thorn”). Lecz o jego profesji poza deklaracją nieboszczyka przypominało tylko niewiele warte pudełko z literami - „1 Schachtel mit Buchstaben - 16 gr.” J.Ch. Jungmann nie miał żadnego własnego warsztatu pracy ani mebli, albowiem takiego majątku nie wymieniono w spisach pośmiertnych. Może żył ze zleconych drobnych prac wykonywanych dla miejscowych introligatorów, drukarni, ewentualnie ze współpracy z miedziorytnikami, wykonując drobne usługi drukarskie. To tylko jednak przypuszczenia, na poparcie których nie znajduję dostatecznych dowodów.

Zachowane materiały, nawet $\mathrm{w}$ porównaniu $\mathrm{z}$ innymi dokumentami postępowania spadkowego, które zawiera tom $\mathrm{z}$ inwentarzami pośmiertnymi ${ }^{18}$, nie są

${ }^{14}$ Zygmunt Mocarski, Książka w Toruniu do roku 1793. Zarys dziejów, Toruń 1934 (odbitka z: Dzieje Torunia), s. 103. W innym miejscu (s. 105, przyp. 589a) Z. Mocarski nie szczędzi jednak J.Ch. Jungmannowi przygany, posądzając go o zły smak.

${ }^{15} \mathrm{Z}$ dobrze udokumentowanych prac Z. Mocarskiego oraz opinii S. Salmonowicza (op.cit., s. 377, przyp. 22), wynika, że odmiennie aniżeli w przypadku Gdańska i Elbląga dla oficyn toruńskich zachowały się pierwszorzędne materiały rachunkowe, które pozwalają na podjęcie studiów nad ekonomią drukarni miejskiej w XVIII w.

${ }^{16}$ S. SAlmonowicz, op.cit., s. 378-379. Zob. Maria Dunajówna, Z dziejów toruńskiego czasopisma „Thornische Wöchentliche Nachrichten und Anzeigen” (1760-1772), Toruń 1960, s. 33.

${ }^{17}$ S. Salmonowicz, op.cit., s. 379.

${ }^{18}$ Tom przechowywany w: APGd., sygn. 300, 1/156, s. 1-537, zawiera 64 pakiety z inwentarzami pośmiertnymi z towarzyszącymi dokumentami rozliczeń finansowych (rachunki pogrzebowe, wierzytelności i inne dokumenty mające wpływ na masę spadkową) z lat 1778-1779. Dokumentację tworzył prowadzący sprawy licytator Samuel Gottlieb Fischer, który zmarł 14 I 1792 r., w wieku 78 lat. Zob. „Danziger Monathliche Sammlung” (Biblioteka Gdańska PAN, Ms. 150, bez paginacji, 
zbyt obfite. Niemniej nawet z całą swą lakonicznością pozwalają na rzucenie nieco światła na ostatnie dni w życiu tej zapomnianej postaci. Są to: zestawienie wydatków pogrzebowych z 31 X $1778 \mathrm{r}^{19}$, inwentarz pośmiertny mienia J. Ch. Jungmanna spisany 2 XI 1778 r. $^{20}$, jak również dokonany 6 listopada urzędowy szacunek wartości dóbr znalezionych przy zmarłym ${ }^{21}$, dwa pokwitowania wystawione przez zaspokojonych w swoich roszczeniach wierzycieli nieboszczyka (6 i 8 XI 1778 r.) ${ }^{22}$, ostatecznie podpisany przez syna Johanna - Gottfrieda - bilans z wartością netto spadku $^{23}$.

Zanim przejdę do tych dokumentów, warto nieco przybliżyć standardowe postępowanie spadkowe podejmowane w nowożytnym Gdańsku ${ }^{24}$. Gdy nie było wątpliwości co do naturalnych przyczyn zgonu, jedną z pierwszych czynności było zabezpieczenie oraz spisanie z natury spadku, tj. wszystkich posiadających wartość rzeczy należących do denata lub będących $\mathrm{w}$ jego władaniu. Inwentarz z natury mógł wykonać główny spadkobierca lub w przypadku nieobecności przełożeni zmarłego (majątek zmarłych żołnierzy spisywali często ich oficerowie, dowódcy; marynarzy - szyprowie; czeladników, uczniów ich pracodawcy, chlebodawcy - mistrzowie; służby - państwo domu) lub też właściciele domu, w którym zamieszkiwał lub czasowo przebywał nieboszczyk (gospodarze karczmy, zajazdu). Najczęściej jednak w celu uniknięcia ewentualnych kłopotów wykonaniem spisu zajmował się wezwany w tym celu licytator („Ausruffer”) - wykwalifikowa-

zapiski w układzie chronologicznym). Według notatki w tej rękopiśmiennej gazecie S.G. Fischer był synem toruńskiego ławnika (chodzi zapewne o iglarza Daniela Fischera pełniącego funkcję ławnika nowomiejskiego w latach 1736-1760, zob. Jerzy DygdaŁA, Urzędnicy miejscy Torunia (1651-1793). Spisy, cz. 3: 1651-1793, Toruń 2002, nr 442).

${ }^{19}$ APGd., sygn. 300, 1/156, s. 177, zestawienie kosztów pochówku „welche ich bey der Beerdigung meines lieben seel. Vaters Johann Christoph Jungmann betrieben habe”, przekazane przez syna zmarłego Johanna Gottfrieda Jungmanna.

20 „Inventarium von dem Nachlaße des unterm 27. October 1778 verstorbenen Johann Christoph Jungmann gewesenen Buchdruckers in Thorn. Wie selbige in des E. Daniel Grebers Bürgers und Flachsbinder Behausung in der Kater-Gaße officiose ist verzeichnet werden" (APGd., sygn. 300, 1/156, s. 163-166).

${ }^{21}$ „Auf Nachgeben E. Hochedl. Gestr. Bürgermeisterlichen und Caduc Amts, habe die Verlaßenschaft des seel. verstorbenen Johann Christoph Jungmann in seiner Behausung geschätzet" (ibid., s. 171-172, 179). Szacunek przeprowadził S.G. Fischer.

${ }^{22}$ Ibid., s. 173 (potwierdzenie uregulowania 24 fl. czynszu za wynajęty domu, 8 XI 1778 r.); s. 175 (potwierdzenie otrzymania wierzytelności - 36 fl., 6 XI 1778 r.).

${ }^{23}$ Ibid., s. 168-169. Bilans został przygotowany przez urząd licytatora.

${ }^{24}$ Opublikowana w kilku ostatnich latach literatura badawcza na temat gdańskich i pruskich inwentarzy pośmiertnych oraz licytacyjnych jest bardzo obfita. Ostatnio powstały trzy książki podejmujące zagadnienie spadkobrania oraz inwentarzy pośmiertnych w Gdańsku i w Prusach Królewskich, które w sposób wyczerpujący omawiają to zagadnienie $\mathrm{z}$ odpowiednią literaturą przedmiotu: Ewa BARYlEWSKA-SzymańsKa, Od piwnic po strych. Wnętrza domów gdańskich drugiej połowy XVIII wieku, Warszawa-Gdańsk 2015; Piotr KiтowsкI, Sukcesja spadkowa w mniejszych miastach województwa pomorskiego w II połowie XVII i XVIII wieku. Studium prawno-historyczne, Warszawa 2015; Edmund KIzIK, Bilans na koniec życia. Gdańskie inwentarze pośmiertne z 2 połowy XVII I XVIII wieku (w druku). 
ny urzędnik Urzędu Kaduków dzierżawiący swoje stanowisko od rady miejskiej. Współpracował on z urzędowym pisarzem, tragarzami, odnajmując od cechu tragarzy pomieszczenia magazynowe $\mathrm{w}$ domu tej korporacji. W ramach wynagrodzenia licytator z pisarzem pobierali procent od spisanego majątku. Według ordynacji o kadukach z 1 IX 1684 r. pracownicy Urzędu Kaduków otrzymywali za pracę przy majątku oszacowanym na sumę do 100 florenów (fl.) - 9 fl. (czyli nie mniej niż 9\% wartości majątku), do $500 \mathrm{fl}$ - $15 \mathrm{fl}$. (3\%), a od $500 \mathrm{fl}$ - $25 \mathrm{fl}$. (maksymalnie do $2,5 \%$ wartości majątku ${ }^{25}$. Suma była dzielona na trzy części między pisarza, instygatora kaduków oraz posłańców urzędu. Ordynacja Urzędu Wiceprezydującego Burmistrza (1731)26 stanowiła, że „cursor” za przeprowadzenie czynności sprawdzających (,vor seine Viligantz”) otrzymywał od każdej sprawy 1 fl. i 6 gr. Według stawek określonych w Caduk-Ordnung z 18 VI 1777 r. pobory wypłacane $\mathrm{z}$ kamlarii nominalnie pozostały na poziomie z XVII w., tj. 150 fl. przysługiwało instygatorowi i $50 \mathrm{fl}$. gońcowi ${ }^{27}$. Za tę ryczałtową sumę zobowiązani byli do spisywania majątków, które nie dawały im żadnego zarobku, czyli mienia nędzarzy.

Pierwotny spis inwentarzowy (często jeszcze bez szacunków wartości poszczególnych rzeczy) miał na celu ochronę majątku przed rozkradzeniem. Służył ochronie praw wszystkich osób powołanych do spadkobrania lub mających uzasadnione pretensje materialne do nieboszczyka. Majątek ujawniony i spisany po śmierci ich właściciela stawał się przedmiotem dochodzenia przez strony postępowania. Miejskich urzędników z Urzędu Kaduków interesowało, czy spadek ma dziedziców, albowiem na mocy przywileju króla Jana Kazimierza z 1660 r. prawo kaduka zostało przeniesione na rzecz Gdańska. Miasto kosztowało to dodatkowe 50 tysięcy fl. (umowa z 30 IV 1660 r.) ${ }^{28}$. Na mocy porozumienia król zachowywał sobie jedynie prawo do dysponowania skonfiskowanymi majątkami zdrajców stanu oraz kadukami wycenionymi na ponad 50 tysięcy florenów. Zaistniały stan prawny potwierdzany przez kolejnych władców polskich utrzymał się aż po schyłek autonomii gdańskiej w 1814 r.

Sporządzony urzędowo inwentarz majątku był również dokumentem zabezpieczającym spadkobierców, krewnych zmarłego, którzy w momencie przyjęcia spadku ponosili odpowiedzialność finansową za długi spadkodawcy. Jednak po wykonaniu inwentarza odpowiedzialność spadkobierców była jedynie ograniczona do wysokości wartości dóbr wyszczególnionych w spisie (recypowaną z prawa rzymskiego instytucją „dobrodziejstwa inwentarza” - beneficium inventarii). Gdy nie było na miejscu członków rodziny, spadkobierców, to kwestie zorganizowania pochówku oraz opieki nad samym majątkiem przyjmowało z urzędu miasto, które,

\footnotetext{
${ }^{25}$ Caduc Ordnung z 1 IX 1684 r. (Biblioteka Gdańska PAN, Ms 733, k. 56r-63r.).

${ }^{26}$ Ordonnance des Vice Amtschen Cursoris, 1731 r., w: APGd., sygn. 300, 5/158, s. 279.

${ }^{27}$ Druk ordynacji o kadukach z 1777 r. w: ibid., sygn. 300, 93/40; tekst ordynacji z 1777 r. opublikowany w: [Christian Karl] Leman, Provinzialrecht der Provinz Westpreußen, Bd. 3: Die Statutarrechte der Stadt Danzig, hrsg. v. Friedrich Heinrich von Strombeck, Leipzig 1832, s. 353-365.

${ }^{28}$ Przywilej opublikowany w: Max Bär, Das Kadukrecht der Stadt Danzig, Zeitschrift des Westpreußischen Geschichtsvereins, H. 51: 1909, s. 45-46.
} 
gdy mimo upływającego czasu nie ujawnili się spadkobiercy, przeprowadzało procedurę zlicytowania masy spadkowej w celu uzyskania gotówki. Z reguły było to związane z tworzeniem kilku kolejnych inwentarzy zawierających szacunek wartości oraz rachunku policytacyjnego, czyli praktycznie powstawały co najmniej trzy inwentarze: 1) rzeczowy bez oszacowania wartości; 2) rzeczowy z szacunkiem wartości mienia; 3) licytacyjny z sumą uzyskaną ze sprzedaży. Z pozyskanej gotówki regulowano wszelkie udokumentowane wierzytelności (pisemne rachunki). Pierwszeństwo miały zawsze koszty pogrzebu (rachunki z kościołów). Następnie zaspakajano pożyczkodawców, którzy na piśmie wnosili do licytatora pretensje do masy spadkowej. Na tym etapie prowadzący postępowanie przeprowadzali zbilansowanie wartości masy spadkowej, odliczając z masy brutto wszelkie poniesione wydatki. Dopiero wtedy majątek netto trafiał do prawowitych spadkobierców.

Dokumentacja sporządzona po śmierci J.Ch. Jungmanna odzwierciedla procedurę znaną z dziesiątek innych materiałów. Po stwierdzeniu zgonu majątek został wstępnie zabezpieczony, a ciało wydane w celu pochowania. Następnie wykonano spis z natury zabezpieczający masę spadkową (2 listopada). Dopiero później, 6 listopada, otaksowano majątek: spisano gotówkę oraz metale szlachetne, których wartość łatwo było przeliczyć na pieniądz. Kursy walutowe monet, obcych saskich, pruskich, rosyjskich i miejscowych polskich i gdańskich, przeliczono na gdańską jednostkę obrachunkową, czyli guldeny, floreny albo złote (1 złoty $=30 \mathrm{gr}$.). W sumie zmarły miał w gotówce 141 fl., 24 gr. i 1 szeląg. W 1778 r., w chwili zgonu J.Ch. Jungmanna, wartość florena obrachunkowego w srebrze wynosiła 0,140 grama $^{29}$. Dopiero w następnej kolejności na liście wyszczególniono przedmioty w odpowiednich kategoriach: metalowe naczynia, bieliznę, ubrania, na końcu wymieniając książki i ustalając ich szacunkową wartość (126 fl.). Z reguły poszczególne kategorie inwentarzowe wyodrębniano odpowiednimi nagłówkami. Również w przypadku skromnego inwentarza J.Ch. Jungmanna zachowano klasyczny układ, jednak nie podkreślając tego w dokumencie.

Wcześniej pochowano ciało zmarłego i zebrano rachunki, które pozwoliły ustalić wydatki. Ich uregulowanie - jak zaznaczono - miało pierwszeństwo $\mathrm{z}$ masy spadkowej w trwającym procesie. Według zestawionego przez syna dopiero 31 października rachunku pochówek ojca kosztował $65 \mathrm{fl}$. i 1 gr. W tym trumnę nabyto za 21 fl., za kartusz z imieniem i nazwiskiem chowanego, ozdoby (,von den Beschlag") zapłacono 8 fl., gwoździe - 6 gr., dzwonnik otrzymał 6 fl. i 1 gr., 6 tragarzy - 7 fl. i 6 gr., dodatkowo na napiwek („na sztof wina”, czyli 1,4 litra) dano $1 \mathrm{fl}$. 16 gr. ${ }^{30}$, osobno za zniesienie ciała (po schodach?) - 18 gr. Wydatki na rzecz kościoła św. św. Piotra i Pawła to 4 fl. 24 gr., za wypożyczenie mar oraz całunu ża-

${ }^{29}$ Tadeusz Furtak, Ceny w Gdańsku w latach 1701-1815, Lwów 1935, s. 78 (tab. 1).

${ }^{30}$ Dokładnie $1 \mathrm{fl}$., czyli 30 gr. odpowiadało ówczesnej średniej cenie sztofa wina francuskiego. Wina słodkie, reńskie, „petersemin”, kanaryjskie były dwu-, trzykrotnie droższe, zob. T. FurtaK, op.cit., s. 155-158 (tab. 47-50). 
łobnego dano $2 \mathrm{fl}$. Wykopanie grobu kosztowało $1 \mathrm{fl}$. i 6 gr., a przygotowanie ciała (wymycie oraz odzianie nieboszczyka) $2 \mathrm{fl}$. i 6 gr.

Syn Jungmanna złożył 27 X 1778 r. swój podpis na rachunku zawierającym obliczenie zbilansowanego już majątku ojca. W sposób typowy dla metody podwójnej rachunkowości dokonał zestawienia strony „winien” ze stroną „ma”. Po naniesieniu według dostarczonych dokumentów poszczególnych pozycji („laut Taxation”, „laut Zettel”, „laut Schein”) dokonano zliczenia pasywów i aktywów, ustalając wartość netto spadku. W gotówce („An baaren Gelde”) oraz oszacowanych ruchomościach („An Mobiliar Vermögen laut Taxation”) wyliczono jego wartość na $267 \mathrm{fl}$. 24 gr. i 1 szeląg. Po stronie prawej („passiv Schulden”) zestawiono koszty pochówku (, an Begräbniskosten laut Zettel"), które powiększono, doliczając udokumentowane roszczenia trojga wierzycieli. Były to: czynsz za pół roku w wysokości 24 fl., pożyczki od wdowy Sittart (36 fl.) oraz Georga Hännela (8 fl.). Z kosztami pogrzebu długi wyniosły łącznie $129 \mathrm{fl}$. i 6 gr. Saldo po zbilansowaniu stron rachunków wyliczono na 138 fl. 18 gr. i 1 szeląg. To była wartość spadku przeznaczana dla spadkobierców. Zgodnie z zasadami księgowości po zsumowaniu danych wpisanych po prawej stronie (kwota salda i rozchodów) i zestawieniu ich z sumą ze strony lewej bilans wyszedł na zero.

Co się stało ze spadkiem? Do akt procesu nie dołączono rachunku licytacyjnego ani kosztów potrąceń urzędniczych. Zapewne gotówkę po zlicytowaniu rzeczy i rozliczeniu z urzędnikami zabrał zamieszkały w Tczewie syn Jungmanna, który był jedynym spadkobiercą (nie wzmiankuje się innych powołanych do spadku, nie wiadomo również, czy spisany został testament).

Pośród zachowanych dokumentów największą wartość poznawczą ma sporządzony przez licytatora Samuela Gottlieba Fischera spis rzeczy po zmarłym drukarzu z szacunkiem wartości. Warto chyba udostępnić badaczom ten niewielki, spisany na trzech stronach dokument ${ }^{31}$. Paginacja jest nieco myląca, albowiem między strony inwentarza włożono również dwa podpisane rachunki wierzycieli zgłaszających pretensje do dysponenta masy spadkowej (s. 173-174, 175-176) oraz zestawienie kosztów pogrzebu (s. 177-178) dlatego też na s. 179 następuje dokończenie inwentarza rzeczy po J.Ch. Jungmannie. Lista sporządzona przez licytatora S.G. Fischera została przez niego podpisana 6 XI $1778 \mathrm{r}$. Na podstawie skromnego inwentarza ubioru i bielizny można wyciągnąć kilka wniosków. J.Ch. Jungmann nie prowadził osobnego gospodarstwa domowego, dlatego $\mathrm{w}$ inwentarzu poza skromnym zestawem do spożywania kawy lub herbaty nie znajdujemy żadnych naczyń służących do samodzielnego przyrządzania potraw; brak mebli wskazuje, że odnajmował izbę z niezbędnym wyposażeniem.

Pierwotny spis został sporządzony $\mathrm{w}$ formie tabeli, a sumy zliczone na końcu stron przenoszono na kolejne strony zestawienia. Zostało to pominięte $\mathrm{w}$ niniejszym odpisie. Tekst $\mathrm{w}$ transkrypcji został poddany nieznacznym zabiegom modernizacyjnym, rozwiązano skróty, zmieniono zapis jednostek pieniężnych. Jeśli

${ }^{31}$ APGd., sygn. 300,1/156, s. 171-172, 179. 
nie podano inaczej, wyjaśnienia dotyczące tkanin i odzieży podano za słownikiem Ireny Turnau ${ }^{32}$.

\footnotetext{
${ }^{32}$ Irena TuRnAU, Słownik ubiorów. Tkaniny, wyroby pozatkackie, skóry, broń i klejnoty oraz barwy znane w Polsce od średniowiecza do początku XIX w., Warszawa 1999.
}

\section{ANEKS ŹRÓDŁOWY}

Inwentarz Johanna Christopha Jungmanna zmarłego w Gdańsku drukarza toruńskiego (1778).

Or. Archiwum Państwowe w Gdańsku, sygn. 300,1/156, s. 171-172, 179.

$<$ s. 171> Auf Nachgeben E[uer]. Hochedl[en]. Gestr[engen] Bürgermeisterlichen und Caduc Amts, habe die Verlaßenschaft des seel[igen] verstorbenen Johann Christoph Jungmann in seiner Behausung geschätzet

2 in Silber eingefasste Hembde Knöpfe 1 fl. 6 gr.

1 alte mess[ingsche] Zucker Dose $1 \mathrm{fl} .26$ gr.

1 mess[ingscher] Thee-Löffel, 1 Kleine Spritze, 1 zinnener Löffel, 2 blech[er]ne Masse - 15 gr.

6 Unter Hembde $-6 \mathrm{fl}$

3 Tisch-Tücher $-4 \mathrm{fl}$.

4 paar Ermeln - 24 gr.

4 Hals-Kragen -18 gr.

7 Hals Binden -6 gr.

5 Schnupftucher - 18 gr.

1 Handtuch, 1 Serviette -1 fl. 6 gr.

2 weisse Kissen Bühren,

1 alte dito $-1 \mathrm{fl} .15 \mathrm{gr}$.

2 alte baumwollene Mütze -6 gr.

$<$ s. $172>5$ paar alte weisse leinen Strümpfe -12 gr.

3 leinwandten Säcke $-1 \mathrm{fl}$.

1 seiden Tuch -1 fl. 15 gr.

1 schwarzt lackens Kleid - $10 \mathrm{fl}$.

1 coul[eurner] Tuchen Rock - $14 \mathrm{fl}$.

1 blau zeugner ${ }^{1}$ Anzieh Peltz - $12 \mathrm{fl}$.

1 alte grosdetourne ${ }^{2}$ Weste $-2 \mathrm{fl}$.

${ }^{1}$ Cajg - tania tkanina wełniana lub półwełniana. Zapewne chodzi o płaszcz podbity futrem.

${ }^{2}$ Grodetur - rodzaj dobrej jakości gęstej jedwabnej lub półjedwabnej tkaniny. 
1 schwartz lackens dito - 2 fl. 15 gr.

1 schwartz Calemanken ${ }^{3}$ dito $-3 \mathrm{fl}$.

1 paar lackens Hosen -2 fl. 15 gr.

1 paar Triepene ${ }^{4}$ dito $-4 \mathrm{fl}$.

2 zerißene Brusttu[e]cher $-1 \mathrm{fl}$.

1 alter Calemanken Schlafrock - $7 \mathrm{fl}$.

1 paar wollne Strümpf - $1 \mathrm{fl} .6 \mathrm{gr}$.

1 paar bieberhaarne Handschuh -6 gr.

1 ledern Pass - 12 gr.

1 Huth, 2 Paruquen, 1 Paar Stiefel, 1 Paar Schuh - 3 fl. 18 gr.

3 Unter, 1 ober Bett, 3 Kissen - 24 fl.

1 Rohrstock - $1 \mathrm{fl}$.

1 Stock Violin -6 gr.

1 Cofree mit Leder bezogen $-3 \mathrm{fl}$.

<s. 179> 1 dukaten Gewicht -6 gr.

1 Schachtel mit Buchstaben - 16 gr.

1 Klein Schreib Pulpet - 15 gr.

1 kleine fichtene Kiste $-1 \mathrm{fl} .15 \mathrm{gr}$

3 alte Bilder -6 gr.

1 parthey alt Maculatur - $5 \mathrm{fl}$.

1 parthey alte Bücher $-5 \mathrm{fl} .{ }^{5}$

[Suma] - $126 \mathrm{fl}$.

Dantzig, den, 6 . Novemb[ris] ${ }^{\star} 1778$

Samuel Gottlieb Fischer, Ausruffer.

prof. dr hab. Edmund Kizik

Instytut Historii PAN

e-mail: filcek@ug.edu.pl

\footnotetext{
${ }^{3}$ Kałamajka - tania, niskogatunkowa tkanina wełniana, często drukowana w kwieciste wzory.

${ }^{4}$ Tryp - połyskująca usztywniona tkanina jedwabna z jedwabiu gorszego gatunku.

${ }^{5} \mathrm{~W}$ pierwszym inwentarzu sprecyzowano nieco tematykę książek: „1 großer Sack mit alten diversen Bücher betreffende die Erfindung der Buchdrucker Kunst”, zob. APGd., sygn. 300, 1/156, s. $156,165$.
} 


\section{DAS NACHGELASSENE INVENTAR DES THORNER DRUCKERS JOHANN CHRISTOPH JUNGMANN VON 1778}

\section{Zusammenfassung}

Schlüsselwörter: Geschichte des Buchdrucks, Königliches Preußen, Schlesien, 18. Jahrhundert, Erbverfahren, Beerdigungen, Danzig, Thorn

In den Jahren 1750-1759 war Johann Christoph Jungmann der Pächter einer Druckerei in Thorn. Er wurde mit einiger Sicherheit um 1700 geboren und war ab 1729 Drucker in Jauer in Schlesien, von wo er 1750 nach Thorn kam. Er war u. a. Herausgeber eines Thorner Gesangbuchs (1752) und eines kunstvoll ausgeführten Drucks zur 300-Jahr-Feier der Verbindung Thorns und des Königlichen Preußens mit der Krone Polen im Jahr 1754. Von der Tätigkeit Jungmanns nach 1759 wusste man nichts und seine Person wurde sogar im Thorner Biographischen Lexikon nicht berücksichtigt. Durch Dokumente, die im Staatsarchiv in Danzig aufgefunden wurden, ist nun bekannt, dass Jungmann am 27. Oktober 1778 in Danzig starb und in der Kirche St. Peter und Paul begraben wurde. Nach seinem Tod wurde ein Erbverfahren durchgeführt, bei dem ein Inventar des Besitzes des Verstorbenen angefertigt und seine Schulden berechnet wurden; dabei wurden auch die Kosten für die Beerdigung bezahlt. Das Erbe des Vaters erhielt sein in Dirschau lebender Sohn. Die wiederentdeckten Dokumente erlauben es, das Lebensende Jungmanns besser zu beleuchten und an seine herausgeberische Leistung zu erinnern.

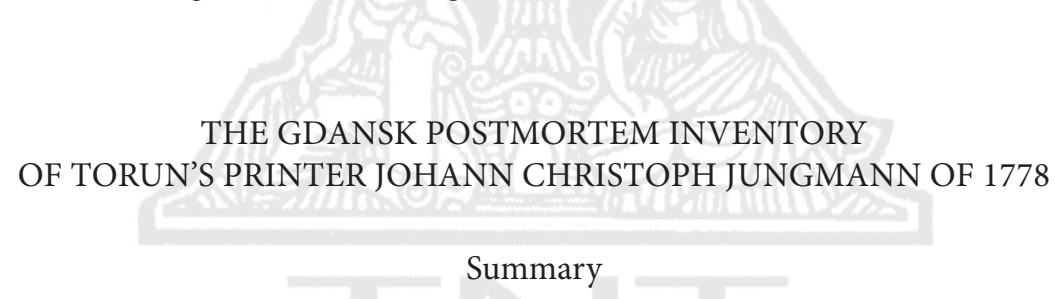

Key words: the history of printing, Royal Prussia, Silesia, the $18^{\text {th }}$ century, inheritance proceedings, funerals, Gdansk, Torun

In the years 1750-1759, Johann Christoph Jungmann was a tenant of the printing house in Torun. He was probably born around 1700 and from 1729 he was a printer in Jaworze in Silesia, from which he moved to Torun in 1750 . He published, for example, the Torun hymnal (1752) and the artistic print to commemorate the $300^{\text {th }}$ anniversary of incorporating Torun and Royal Prussia into the Crown in 1754. The activity of J.Ch. Jungmann after 1759 is not known; he was even omitted from the Torun biographic dictionary. Basedon documents found in the State Archive in Gdansk, it is known that J.Ch. Jungmann died in Gdansk on 27 October 1778 and was buried in the church of Saints Peter and Paul. After his death the inheritance proceedings took place; the inventory of his property was carried out, his debts were paid and the costs of his funeral were covered. The heir of his wealth was his son who lived in Tczew. This documentation has allowed us to learn about the life of J.Ch. Jungmann and remember his publishing legacy. 